OESOPHAGUS

\title{
Expression of cyclooxygenase 2, microsomal prostaglandin E synthase 1, and EP receptors is increased in rat oesophageal squamous cell dysplasia and Barrett's metaplasia induced by duodenal contents reflux
}

\author{
T J Jang, S K Min, J D Bae, K H Jung, J I Lee, J R Kim, W S Ahn
}

Gut 2004;53:27-33

Background and aim: It is known that bile acids can induce mucosal injury, stimulate cell proliferation, and promote tumorigenesis. A large body of genetic and biochemical evidence indicate that the biosynthetic pathway of prostaglandin $\mathrm{E}_{2}\left(\mathrm{PGE}_{2}\right)$ may play an important role in human and rodent tumours. Therefore, we examined the expression pattern of cyclooxygenase 1 (COX-1), COX-2, and microsomal prostaglandin E synthase 1 (mPGES-1), as well as EP receptor subtypes in rat oesophageal lesions induced by duodenal contents reflux.

Methods: Oesophagoduodenal anastomosis was performed in rats to induce duodenal contents reflux.

See end of article for authors' affiliations

Correspondence to: Professor T J Jang, Department of Pathology, Dongguk University, College of Medicine, 707 Suekjang-dong, Kyongju, Kyongbuk 780-714, Korea; taejung@ mail.dongguk.ac.kr

Accepted for publication 11 August 2003
We examined histological changes and expression of COX-1, COX-2, mPGES-1, and EP receptor subtypes in the oesophagus by immunohistochemistry and reverse transcription-polymerase chain reaction.

Results: Normal control oesophageal tissues showed COX-1 expression in subepithelial stromal cells, including endothelial cells and muscular cells, and did not reveal expression of COX-2 or mPGES-1. In the case of squamous cell lesions, immunoreactivity of COX-1 was similar to that of normal lesions, and COX2 was maximally expressed around the vascular papillae of tissues showing dysplasia and surrounding epithelial layer and basal layer. mPGES-1 was highly expressed in stromal cells with COX-2 expression. In the case of Barrett's oesophagus, COX-2 and mPGES-1 were predominantly in subepithelial stromal cells. mRNA levels of COX-2, mPGES-1, $E P_{2}, \mathrm{EP}_{3}$, and $\mathrm{EP}_{4}$ were higher in the experimental groups than in controls.

Conclusions: We suggest that the biosynthetic pathway of $\mathrm{PGE}_{2}$ may play an important role in oesophageal squamous cell dysplasia and glandular metaplasia induced by duodenal contents reflux.
$\mathrm{R}$ eflux of duodenal contents in addition to gastric acid in humans seems to contribute to the development of oesophagitis and Barrett's oesophagus. ${ }^{12}$ Experimental studies in the rat have shown that chronic duodenal contents reflux into the oesophagus induces severe oesophagitis and also plays a role as a cocarcinogenic factor by increasing the number of oesophageal carcinomas when a carcinogen is given simultaneously. ${ }^{3-5}$ Moreover, chronic refluxed duodenal contents per se caused squamous cell carcinoma, adenosquamous carcinoma, and adenocarcinoma. ${ }^{6-8}$ Although the precise mechanism by which duodenal reflux causes oesophageal injury and predisposes to neoplasia is uncertain, there is considerable evidence that bile acids can induce mucosal injury, stimulate cell proliferation, and promote tumorigenesis. ${ }^{9}$ Two isoforms of cyclooxygenase 1 (COX-1) and COX- 2 have been characterised in mammalian and avian species. COX-1 is constitutively expressed in most tissues to maintain stable physiological conditions whereas COX-2 is transiently induced by proinflammatory cytokines and growth factors, and involved in inflammation and mitogenesis. ${ }^{10}$ Recent studies have shown that the constituents of gastro-oesophageal reflux, including acid and bile, can regulate COX-2 expression. ${ }^{11}{ }^{12}$ COX-2 is upregulated in reflux oesophagitis, Barrett's oesophagus, and oesophageal carcinoma. ${ }^{12-14}$ In addition, use of COX-2 inhibitors results in a reduction in the development of oesophageal adenocarcinoma induced by duodenal reflux. ${ }^{15}$
COX catalyses the conversion of arachidonic acid to prostaglandin $\mathrm{G}_{2}\left(\mathrm{PGG}_{2}\right)$ and $\mathrm{PGH}_{2}$. $\mathrm{PGH}_{2}$ is subsequently converted to a variety of prostaglandins that include $\mathrm{PGE}_{2}$, $\mathrm{PGD}_{2}, \mathrm{PGF}_{2}, \mathrm{PGI}_{2}$, and thromboxane $\mathrm{A}_{2}$ by each prostaglandin synthase. $\mathrm{PGE}_{2}$ has been shown to induce malignant changes in epithelial cells through immunosuppression, inhibiting apoptosis, increasing the metastatic potential of epithelial cells, and promoting angiogenesis. ${ }^{16-20}$ Two segregated biosynthetic pathways have been described for $\mathrm{PGE}_{2}$ biosynthesis. These pathways synthesise $\mathrm{PGE}_{2}$ via prostaglandin E synthase (PGES) functionally linked to either COX1 or COX-2. ${ }^{21}$ At least three PGES enzymes, including cytosolic PGES, microsomal prostaglandin E synthase 1 (mPGES-1), and mPGES-2 have been identified.2. ${ }^{23}$ Induced expression of mPGES-1 has been postulated to be associated with various pathophysiological events in which COX-2 derived $\mathrm{PGE}_{2}$ has been implicated, such as rheumatoid arthritis, febrile response, reproduction, bone metabolism, and Alzheimer's disease. ${ }^{21}{ }^{24-27}$ In addition, mPGES- 1 is

\footnotetext{
Abbreviations: COX, cyclooxygenase; mPGES-1, microsomal prostaglandin E synthase 1; PG, prostaglandin; BrdU, bromodeoxyuridine; RT-PCR, reverse transcription-polymerase chain reaction; GAPDH, glyceraldehyde 3-phosphate dehydrogenase; VEGF, vascular endothelial growth factor; HIF- $1 \alpha$, hypoxia inducible factor $1 \alpha$; NSAIDs, non-steroidal anti-inflammatory drugs
} 
over expressed in colorectal cancers, non-small cell lung cancers, and endometrial cancers. ${ }^{28-30}$ A recent study showed that mPGES-1 directed cellular transformation was accompanied by changes in the expression of a variety of genes related to proliferation, morphology, adhesion, and the cell cycle. ${ }^{31} \mathrm{PGE}_{2}$ mediates its effects, in part, through $\mathrm{G}$ protein coupled PGE receptors, designated $\mathrm{EP}_{1}, \mathrm{EP}_{2}, \mathrm{EP}_{3}$, and $\mathrm{EP}_{4}{ }^{32}$ $\mathrm{EP}_{1}$ and $\mathrm{EP}_{4}$ knockout mice showed a reduction in the number of aberrant crypt foci that develop in mice following azoxymethane treatment. ${ }^{33}{ }^{34}$ Moreover, mRNA expression of $\mathrm{EP}_{2}$ and $\mathrm{EP}_{4}$ was increased in human cervical and endometrial cancer tissues compared with normal tissues. ${ }^{3035}$

We examined the pattern of COX-2 and mPGES-1 expression, as well as EP receptor subtypes, to elucidate the relationship between arachidonate metabolism and oesophageal tumorigenesis induced by chronic duodenal reflux.

\section{MATERIAL AND METHODS Animals}

Thirty seven week old male Sprague-Dawley rats (Kist, Taejun, Korea) were used for the control $(n=8)$ and experimental $(n=29)$ groups. Throughout the experiment, all rats were housed in a controlled environment with a 12 hour light/dark cycle and a temperature of $22(2)^{\circ} \mathrm{C}$. After an acclimatisation period of one week, 29 experimental rats were randomly divided into five groups in a time course design and underwent an oesophagoduodenstomy to induce duodenal contents reflux for $10(n=2), 20(n=12), 30$ $(n=8)$, and $40(n=7)$ weeks, respectively. At the end of the appropriate time period for each group, the control and experimental rats were killed with ether.

\section{Surgical technique and tissue samples}

Solid food was withdrawn for 24 hours and water for 12 hours before surgery. Anaesthesia was induced and maintained with an isoflurane-air mixture. Oesophagoduodenal anastomosis was performed according to the Clark model. ${ }^{4}$ In brief, a midline laparatomy was performed, and the gastro-oesophageal junction was identified and mobilised while carefully preserving the vagus nerve. The gastro-oesophageal junction was ligated, and the distal oesophagus was transected $2 \mathrm{~mm}$ above the ligature. A total of eight polypropylene 7-0 sutures were placed. A $5 \mathrm{~mm}$ transverse enterostomy was created on the antimesenteric border of the duodenum, $1 \mathrm{~cm}$ distal to the pylorus. An end to side oesophagoduodenstomy was performed. To compensate for blood loss, $1 \mathrm{ml}$ of sterile $0.9 \% \mathrm{NaCl}$ was instilled into the peritoneal cavity. The abdominal incision was closed in two layers and postoperatively the rats were allowed to drink water after six hours and were fed the following day.

Rats were given a single intraperitoneal injection of $0.1 \mathrm{mg} / \mathrm{g}$ body weight of bromodeoxyuridine (BrdU) (Sigma Chemical Co., St Louis, Missouri, USA), one hour before autopsy. Immediately after death, the entire oesophagus, contiguous anastomotic site, and $0.7 \mathrm{~cm}$ of duodenal mucosa were removed and the lumen was longitudinally opened. After snap freezing, a representative sample of the upper and lower oesophagus were stored at $-70^{\circ} \mathrm{C}$ for reverse transcription-polymerase chain reaction (RT-PCR). The remaining oesophagus, including the anastomotic site and $0.7 \mathrm{~cm}$ of duodenal mucosa, was fixed in $10 \%$ neutral buffered formalin for 24 hours for histological study and immunohistochemistry.

\section{Pathological analysis}

For histological evaluation, formalin fixed tissues were embedded in paraffin, cut at $4 \mu \mathrm{m}$, and stained with haematoxylin-eosin. Two pathologists blinded to the experimental groups independently assessed all tissues. Squamous epithelial lesions were histologically classified into normal, hyperplasia, papillary hyperplasia, and dysplasia, based on architectural changes and atypical cellular morphology. A diagnosis of Barrett's oesophagus was suspected by the presence of mucus secreting columnar cells surrounded by squamous epithelium above the anastomotic site. In addition, Barrett's oesophagus was divided into short and long, according to the distance from the anastomotic site; it was regarded as long when present at a distance from the anastomotic site. Atypical Barrett's oesophagus was diagnosed when glands with atypical features were present both at the superficial and deep portions of the wall.

\section{Immunohistochemistry}

Serial sections of $4 \mu \mathrm{m}$ thickness were made and spread on poly-L-lysine coated slides. Paraffin sections were immersed in three changes of xylene and hydrated using a graded series of alcohol. Antigen retrieval was performed routinely by immersing the sections in $0.01 \mathrm{M}$ citrate buffer $(\mathrm{pH} \mathrm{6.0)}$ in a pressure cooker by autoclaving for 15 minutes.

Endogenous peroxidase activity was blocked with 3\% hydrogen peroxide for 15 minutes and then incubated with a primary antibody overnight in a humidified chamber at $4^{\circ} \mathrm{C}$. Primary antibodies were polyclonal rabbit anti-COX-1 (Cayman Chemical, Ann Arbor, Michigan, USA) at a dilution of 1:2000, anti-COX-2 antibody (Cayman Chemical) at a dilution of 1:500, anti-mPGES-1 antibody (Cayman Chemical) at a dilution of 1:500, and monoclonal mouse anti-BrdU antibody (Dako, Santa Barbara, California, USA). Staining was achieved with a Dako LSAB+kit and developed with diaminobenzidine tetrahydrochloride (Dako). Sections were counterstained for five minutes with Meyer's haematoxylin and then mounted. Human colon cancer with intense staining for both COX-2 and MPGES-1 was used as a positive control. As a negative control, rabbit and mouse IgG isotypes (Dako) were used instead of primary antibodies. BrdU labelling index was calculated by counting at least 1000 cells in a random 10 high power fields. Estimation of immunohistochemical expression of COX-1 and COX-2 was evaluated according to both intensity and area of signal: 0, absent; 1 , mild; 2, moderate; and 3, severe. Expression of mPGES-1 was assessed as negative or positive.

\section{RNA extraction and RT-PCR}

Total RNA was extracted and purified from frozen lower oesophageal tissues using the GeneElute Mammalian Total RNA kit (Sigma) according to the manufacturer's instructions. RNA was quantified by determining absorbance at $260 \mathrm{~nm}$. Total RNA $(2 \mu \mathrm{g})$ from each sample was reverse transcribed into cDNA using Superscript II reverse transcriptase (Life Technologies, Inc., Rockville, Maryland, USA) and random hexamer primers (Takara, Shiga, Japan). The PCR primers were as follows: glyceraldehyde 3-phosphate dehydrogenase (GAPDH) (311 bp), sense 5'-GAA CGG GAA GCT CAC TGG CAT GGC-3', antisense 5' -TGA GGT CCA CCA CCC TGT TGC TG-3'; COX-1 (443 bp), sense 5'-GAG TCT CTC GCT CCA GTT TCC-3', antisense 5'-GCG AGT ATA GTA GCT CAC GTT GG-3'; COX-2 (448 bp), sense 5'-ATG CTC TTC CGA GCT GTG CT-3', antisense 5' -CAT GGG AGT TGG GCA GTC AT-3'; mPGES-1 (45l bp), sense 5'-ATG ACT TCC CTG GGT TTG GTG ATG GAG-3', antisense 5' -TC ACA GAT GGT GGG CCA CTT CCC AGA-3'; EP 1 (465 bp), sense 5'-GAG GCA ACA ACG TGT GTA ACA-3', antisense 5' -AGC CAT GGC GGC CAG CAG GGC TAG-3'; $\mathrm{EP}_{2}$ (336 bp), sense 5'-TCT GGC AGT AGC CTG AGA GGC-3', antisense 5' -CTG TCC GCA GAG GTC CGT CTG3'; $\mathrm{EP}_{3}$ (412 bp), sense 5' -TCT GTG TCC GTG GCC TTC CCC3', antisense 5'-CAC AGG CAG CAG CGC GAA GGC-3'; $\mathrm{EP}_{4}$ (488 bp), sense: 5' -TTC CGC TCG TGG TGC GAG TGT TC-3', antisense 5'-GAG GTG GTG TCT GCT TGG GTC AG-3'. The 


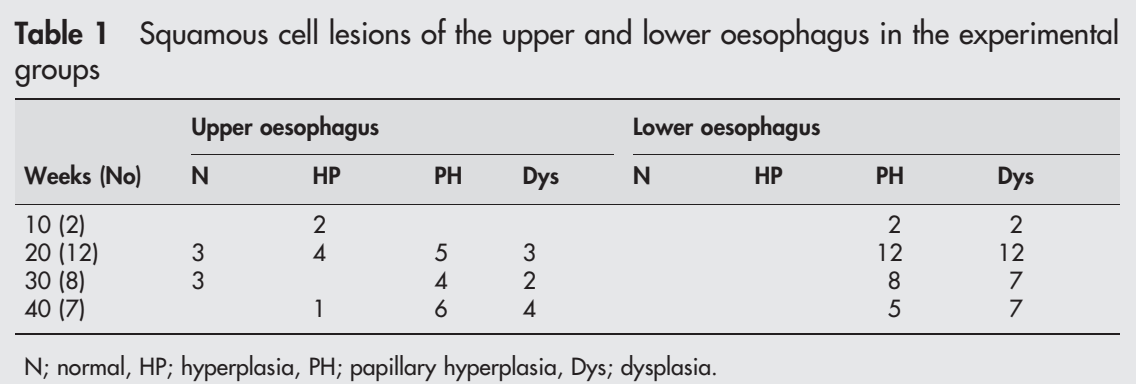

PCR products were electrophoresed on $1.5 \%$ agarose gel containing ethidium bromide and then photographed under UV light.

\section{Statistical analysis}

The significance of differences between groups was evaluated using Fisher's exact test and one way analysis of variance. Differences were considered to be statistically significant at $\mathrm{p}<0.05$.

\section{RESULTS}

\section{Gross findings in the oesophagus of the experimental groups}

Experimental rats showed an abnormally dilated oesophagus, and the oesophageal inner surface displayed whitish nodular patches, which were prominent in the lower oesophagus. There were superficial ulcers located mainly in the lower oesophagus. All of these macroscopic findings were present in all rats and more intense in rats exposed to reflux of duodenal contents for longer periods.

\section{Squamous cell lesions of the upper and lower oesophagus in the experimental groups}

The oesophagus of control rats did not reveal any pathological findings but various squamous cell lesions were seen in the upper and lower oesophagus of experimental rats. As shown in table 1 , squamous cell lesions of the lower oesophagus were more severe than those of the upper oesophagus. Dysplasia in the lower oesophagus occurred at 10 weeks. To assess the biological behaviour of various squamous lesions, we performed immunohistochemical staining for BrdU because the proliferation index is often

Table 2 Bromodeoxyuridine (BrdU) indices of squamous cell lesions of the lower oesophagus in the control and experimental groups

\begin{tabular}{lcc}
\hline & No of lesions & BrdU indices (\%) \\
\hline Normal & 8 & $1.0(0.01)^{*}$ \\
Papillary hyperplasia & 27 & $4.2(1.91)^{*}$ \\
Dysplasia & 28 & $40.7(13.5)$ \\
\hline${ }^{*} \mathrm{p}<0.05$ compared with dysplasia. & \\
\hline
\end{tabular}

increased in dysplastic and cancer tissues. As anticipated, the BrdU labelling index of dysplasia was higher than that of normal and papillary hyperplasia (table 2 ).

\section{Glandular lesions of the lower oesophagus in the experimental groups}

Barrett's oesophagus did not occur in control rats but $86 \%$ of experimental rats showed glandular metaplasia above the oesophagoduodenal junction. The results are shown in table 3. Long and atypical Barrett's oesophagus were restricted to rats exposed to the reflux of duodenal contents for 30 and 40 weeks. Glandular metaplasia originated from the lower oesophagus because all lesions were above the oesophageal anastomosis and had an intact muscularis propria layer on histology. BrdU labelled columnar cells were located in the upper portion of Barrett's oesophagus while in duodenal mucosa they were mainly restricted to within the isthmic portion (data not shown).

\section{Expression of COX-1 and COX-2 in the lower oesophagus}

Normal control oesophageal tissues showed COX-1 expression in subepithelial stromal cells, including endothelial cells and muscular cells, and did not reveal expression of COX-2 (fig 1). In the case of squamous cell lesions in the experimental groups, immunoreactivity of COX-1 was similar to that of normal controls, and there was no significant difference between histological subtypes (data not shown). COX-2 was highly expressed in dysplasia compared with normal tissue and papillary hyperplasia (table 4) (fig 1). As shown in fig. 1, COX-2 was maximally expressed around the vascular papillae of tissues showing dysplasia, and positive staining was also noticeable in the surrounding epithelial layer and basal layer. COX-1 and COX-2 were not labelled in most Barrett's mucosa but in subepithelial stromal cells (fig. 2). Of six cases of atypical Barrett's mucosa, one (17\%) showed cytoplasmic immunoreactivity for COX-2 (fig 2) and five were completely negative. We extracted and purified total RNA from frozen lower oesophageal tissues in control and experimental rats and then performed RT-PCR. In agreement with immunohistochemical results, COX-1 mRNA was expressed in both groups, and expression level of COX-2 mRNA was higher in experimental groups than in controls (fig 3 ).

Table 3 Glandular lesions of the lower oesophagus in the experimental groups

\begin{tabular}{llcll}
\hline Weeks (No) & No BO & Short BO & Long BO & Atypical BO \\
\hline $10(2)$ & 1 & 1 & 0 & 0 \\
$20(12)$ & 2 & 10 & 0 & 0 \\
$30(8)$ & 1 & 1 & 3 & 3 \\
$40(7)$ & 0 & 1 & 3 & 3 \\
\hline \multicolumn{2}{l}{ BO, Barrett's oesophagus. } \\
\end{tabular}



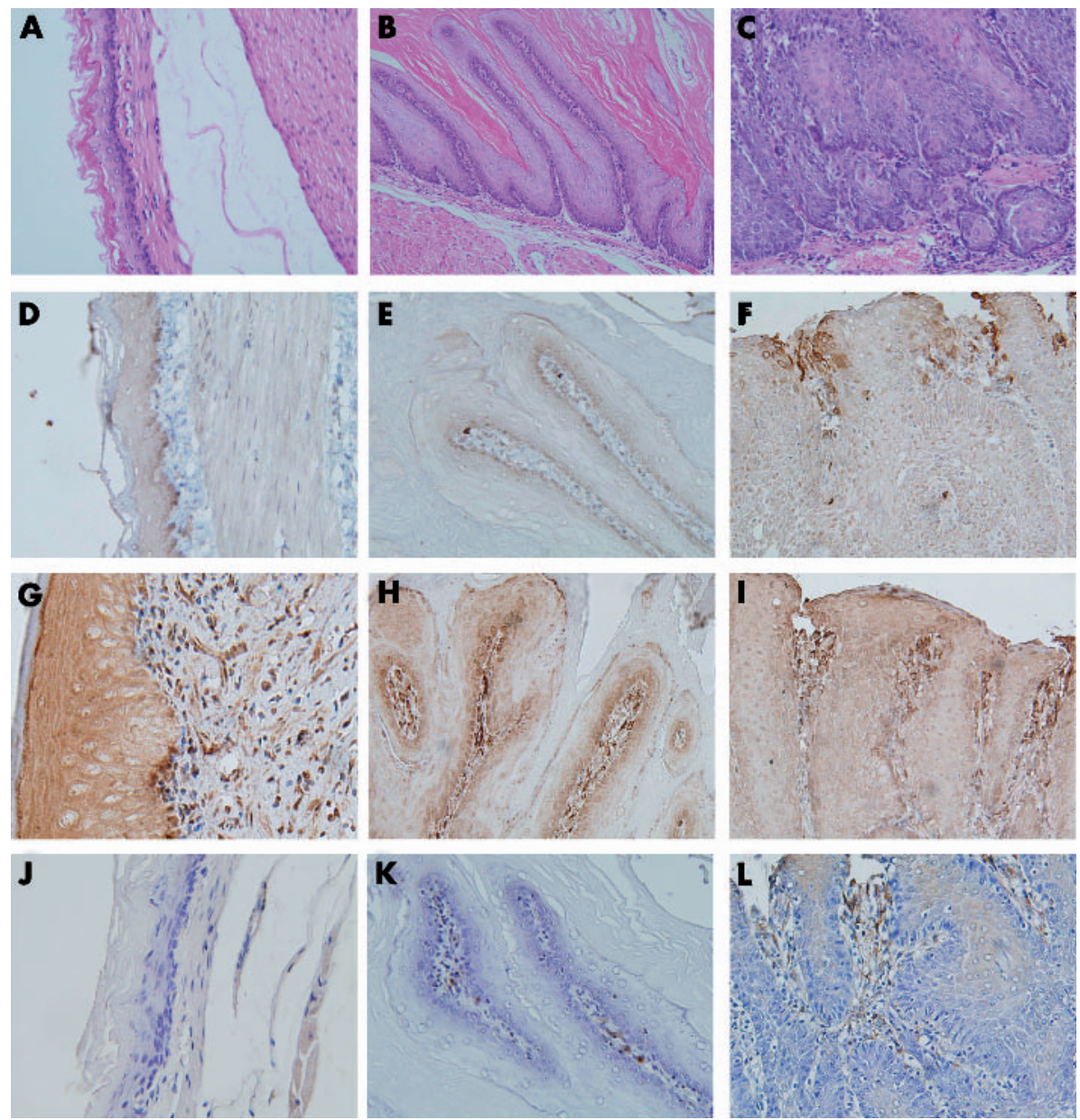

Figure 1 Histology $(A-C)$ and immunohistochemical staining (D-L) of squamous cell lesions in the lower oesophagus. (A, D, G, J) Normal oesophageal tissue; (B, E, H, K) squamous papillary hyperplasia; (C, F, I, L) squamous cell dysplasia; (D-F) cyclooxygenase 2 (COX-2); (G-I) COX-1; (J-L) microsomal prostaglandin E synthase 1 (mPGES-1). COX-2 was maximally expressed around the vascular papillae of tissues showing dysplasia, and positive staining was noticeable in the surrounding epithelial layer and basal layer. COX-1 expression was observed only in the subepithelial stromal cells of normal oesophageal tissue, papillary hyperplasia, and dysplasia. mPGES-1 was expressed only in stromal cells with COX-2 expression in dysplasia. Magnification: $(B, C) \times 200 ;(A, D-L) \times 400$.

\section{Expression of mPGES-1 in the lower oesophagus}

In the case of squamous cell lesions, mPGES-1 expression was enhanced in dysplasia compared with normal tissue and papillary hyperplasia (table 5 ). As shown in fig 1, mPGES- 1 was expressed in stromal cells around the vascular papillae of tissues showing dysplasia. These areas corresponded to regions showing immunoreactivity for COX-2. However, all squamous cells did not display immunoreactivity for mPGES-1. In the case of Barrett's oesophagus, immunolocalisation of mPGES-1 was subepithelial stromal cells and not mucosal cells, unlike the result observed in squamous lesions

Table 4 Immunoreactivity of cyclooxygenase 2 (COX-2) in squamous cell lesions of the lower oesophagus in the control and experimental groups

\begin{tabular}{lcl}
\hline & No of lesions & COX-2 \\
\hline Normal controls & 8 & $0.0(0.01)^{*}$ \\
Papillary hyperplasia & 27 & $0.4(0.52) \dagger$ \\
Dysplasia & 28 & $2.9(0.3)$ \\
\hline \multirow{2}{*}{$p<0.05$ compared with papillary hyperplasia and dysplasia. } \\
$t p<0.05$ compared with dysplasia.
\end{tabular}

(fig 2). Expression level of mPGES-1 mRNA was higher in the experimental groups than in normal controls (fig 3).

\section{mRNA levels of $E P_{1}, E P_{2}, E P_{3}$, and $E P_{4}$ in the lower oesophagus}

We assessed mRNA levels of $\mathrm{EP}_{1}, \mathrm{EP}_{2}, \mathrm{EP}_{3}$, and $\mathrm{EP}_{4}$ in the lower oesophagus by semiquantitative RT-PCR (fig 3). mRNA levels of $\mathrm{EP}_{1}$ were negligible in both the experimental and control groups. In contrast, mRNA levels of $\mathrm{EP}_{2}, \mathrm{EP}_{3}$ and $\mathrm{EP}_{4}$ were higher in the experimental groups than in normal controls.

\section{DISCUSSION}

We have demonstrated a significant role for the biosynthetic pathway of $\mathrm{PGE}_{2}$ in oesophageal squamous cell dysplasia and glandular metaplasia induced by duodenal contents reflux in rats. The correlation between arachidonic acid metabolism and tumorigenesis is suggested by studies on non-steroidal anti-inflammatory drugs (NSAIDs). Long term use of NSAIDs in rheumatic patients is related to a reduced risk of various human cancers, including oesophageal cancer. ${ }^{36}{ }^{37} \mathrm{~A}$ large body of genetic and biochemical evidence supports a role for COX-2 in human and rodent tumours. ${ }^{38}{ }^{39}$ A recent study showed that bile acids play an important role in COX-2 expression of rat reflux oesophagitis caused by oesophagoduodenal anastomosis. ${ }^{11}$ COX-2 was expressed in $91 \%$ of 

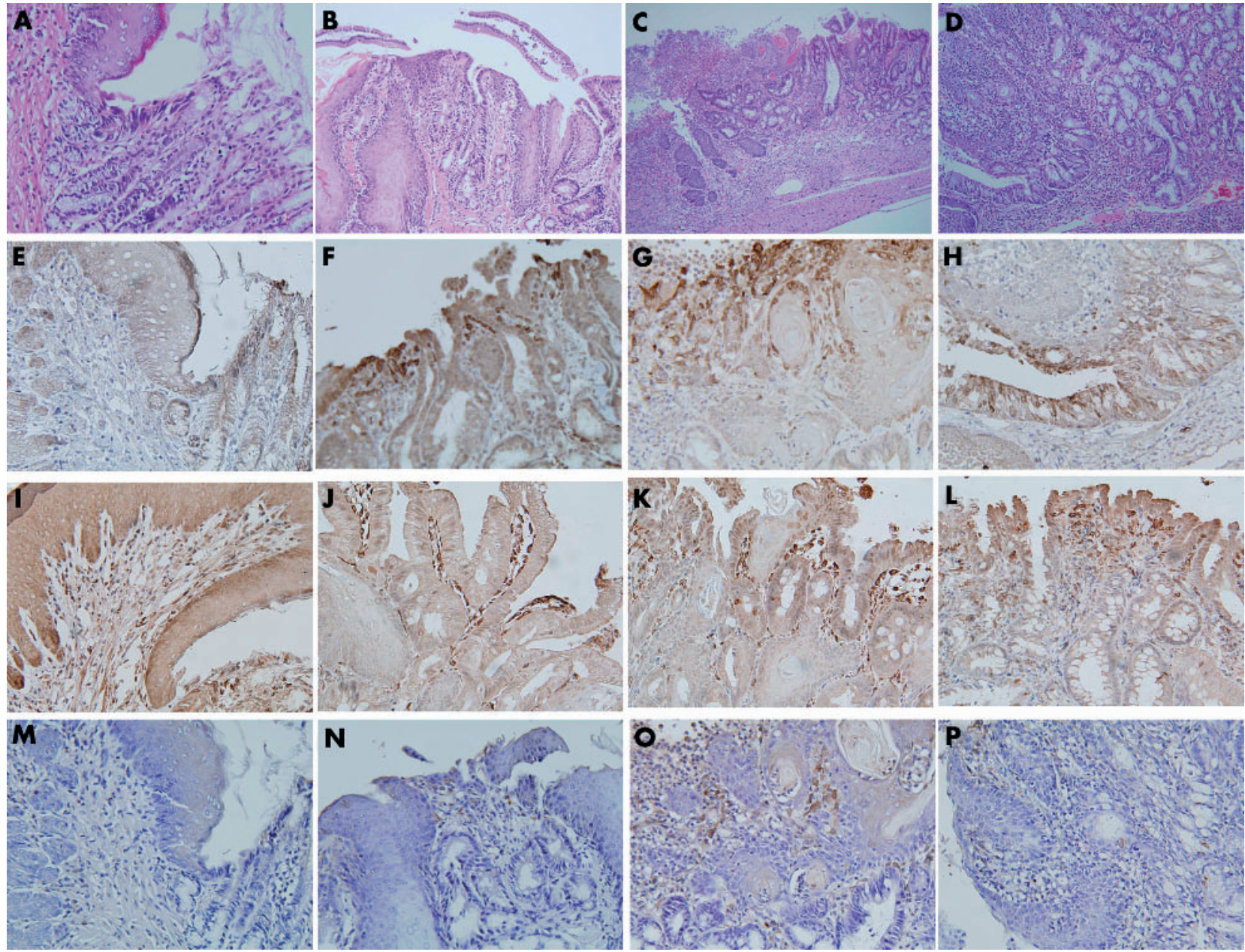

Figure 2 Histology $(A-D)$ and immunohistochemical staining $(E-P)$ of the oesophagogastric junction and Barrett's oesophagus. $(A, E, I, M)$ normal oesophagogastric junction; (B, F, J, N) short Barrett's oesophagus; (C, G, K, O) long Barrett's oesophagus; (D, H, L, P) atypical Barrett's oesophagus; (E-H) cyclooxygenase 2 (COX-2); (I-L) COX-1; (M-P) microsomal prostaglandin E synthase 1 (mPGES-1). The normal oesophagogastric junction showed COX-1 in subepithelial stromal cells and did not express COX-2 or mPGES-1. All types of Barrett's oesophagus showed expression of COX-1, COX-2, and mPGES-1 in subepithelial stromal cells. In atypical Barrett's oesophagus, COX-2 immunoreactivity was observed not only in stromal cells but also in metaplastic columnar cells. Magnification: (C) ×100; (B, D) $\times 200 ;(A, E-P) \times 400$.

human oesophageal squamous cell carcinomas. ${ }^{13}$ In this study, COX-2 was minimally induced in papillary hyperplasia and highly expressed in squamous cell dysplasia. This lesion was also characterised by increased cell proliferation. Prostaglandins can stimulate cell proliferation ${ }^{40}$ but it is uncertain whether enhanced expression of COX-2 is causally linked to increased cell proliferation. However, a recent study showed that rofecoxib reduced cell proliferation in Barrett's oesophagus by inhibiting COX-2 expression and activity. ${ }^{41}$ Therefore, the persistence of increased COX-2 expression in squamous cell dysplasia implies that induction of the COX-2 gene may be necessary for maintenance of the malignant phenotype characterised by increased cell proliferation. Localisation of COX-2 predominantly to stromal cells around vascular papillae and surrounding squamous epithelial cells with basal cells is consistent with published findings in human reflux oesophagitis. ${ }^{12}$ Recently, $\mathrm{PGE}_{2}$ production via the COX-2 catalysed pathway induced vascular endothelial growth factor (VEGF) expression by inducing hypoxia inducible factor 1 (HIF-1) stabilisation and expression. ${ }^{42}{ }^{43}$ Immunostaining for VEGF and HIF-1 may be necessary to evaluate immunolocalisaion of COX-2 in vascular papillae.

Eighty six percent (25/29) of rats undergoing oesophagoduodenal anastomosis developed Barrett's oesophagus but definite adenocarcinoma did not occur. This finding may be explained by the experiment of Chen and Yang. ${ }^{44}$ They reported that iron supplementation promoted the formation of oesophageal adenocarcinoma originated from Barrett's oesophagus induced by the surgical techniques oesophagoduodenal or oesophagogastroduodenal anastomosis. ${ }^{44}$ COX-2 was over expressed in human oesophageal adenocarcinoma. ${ }^{13}{ }^{14}$ Moreover, a selective COX-2 inhibitor suppressed the development of rat oesophageal adenocarcinoma induced by duodenal reflux. ${ }^{15} \mathrm{COX}-2$ expression was also increased in biopsied Barrett's mucosa in response to pulses of acid or bile acids in an ex vivo organ culture system, which was attenuated by a selective COX-2 inhibitor. ${ }^{12}$ Interestingly, in metaplastic Barrett's mucosa, COX-2 expression was observed primarily in the lamina propria, consistent with other studies; ${ }^{12-14}$ however, a shift in staining to the epithelium was observed in 17\% of atypical Barrett's mucosa, suggesting that COX-2 over expression in these cells may constitute a relatively late event.

Elevated expression of mPGES-1 has recently been demonstrated in several human cancers..$^{28-30}$ Murakami et al suggested that aberrant expression of MPGES-1 in combination with COX-2 could contribute to tumorigenesis. ${ }^{21}{ }^{31}$ In this study, mPGES-1 was expressed in squamous cell dysplasia, in which COX-2 was also highly expressed. It seems likely therefore that enhanced expression of mPGES-1 in addition 
E

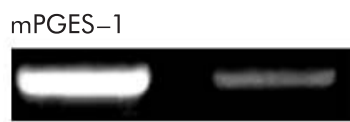

E

$\mathrm{N}$
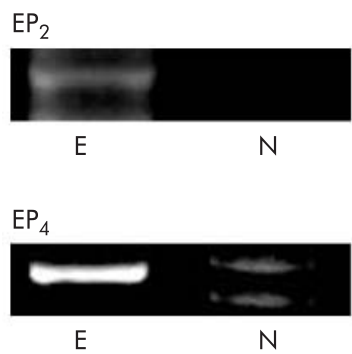

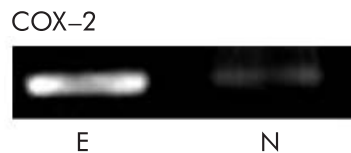

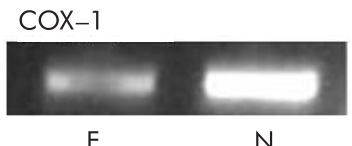

E

$\mathrm{EP}_{1}$

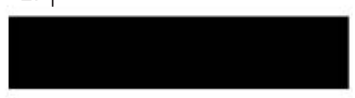

E
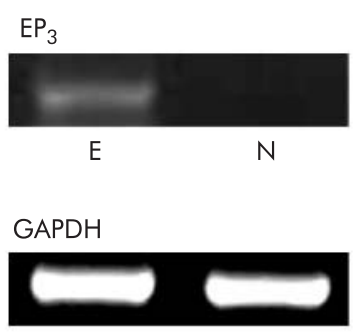

E

N
Figure 3 mRNA levels of cyclooxygenase 1 (COX-1), COX-2, microsomal prostaglandin E synthase 1 (mPGES-1) $\mathrm{EP}_{1}, \mathrm{EP}_{2}, \mathrm{EP}_{3}$, and $\mathrm{EP}_{4}$ in experimental oesophageal tissue (E) and normal controls (N). GAPDH, glyceraldehyde 3-phosphate dehydrogenase.

to COX-2 contributes to the increased amount of $\mathrm{PGE}_{2}$. Bile acids induce COX-2 by stimulating transcription and stabilising mRNA. ${ }^{45}{ }^{46}$ In contrast, mPGES- 1 is not induced by bile acids. ${ }^{45}$ Several proinflammatory cytokines such as tumour necrosis factor and interleukin 1 induce mPGES-1. ${ }^{21} 28$ Therefore, expression of mPGES-1 restricted to stromal cells may be caused by proinflammatory cytokines produced by mucosal injury associated with the reflux of duodenal contents containing bile acids.

Eicosanoids are unstable and their activities are normally restricted to cells in the immediate vicinity that express specific receptors. Binding of $\mathrm{PGE}_{2}$ to its receptors initiates the signalling mediated by receptor subtype specific $G$ proteins and respective changes in second messengers. ${ }^{47}$ Therefore, we examined the $\mathrm{PGE}_{2}$ receptors of the lower oesophagus by RT-PCR. Interestingly, mRNA levels of $\mathrm{EP}_{2}$, $\mathrm{EP}_{3}$, and $\mathrm{EP}_{4}$ were increased in experimental oesophageal tissue showing squamous dysplasia compared with normal controls. This is in accordance with other studies. ${ }^{30} 35$ Recently, Yang et al demonstrated an important role for the $\mathrm{EP}_{2}$ receptor in $\mathrm{PGE}_{2}$ induced inhibition of dendritic cell differentiation and function and diminished antitumour cellular immune responses. ${ }^{48}$ Another study reported the significance of $\mathrm{PGE}_{2}-\mathrm{EP}_{3}$ receptor signalling in tumour development and angiogenesis. ${ }^{49}$ In addition, $\mathrm{EP}_{4}$ knockout mice showed a reduction in the number of aberrant crypt foci that develop in mice following azoxymethane treatment. ${ }^{33}$ In contrast, Konger et al reported that loss of $\mathrm{EP}_{2}$ receptor in immortalised human keratinocytes resulted in increased

Table 5 Immunoreactivity of microsomal prostaglandin E synthase 1 in the squamous cell lesions of the lower oesophagus in normal controls and experimental groups

\begin{tabular}{lcc}
\hline & Positive & Negative \\
\hline Normal controls & 0 & 8 \\
Papillary hyperplasia & 3 & 24 \\
Dysplasia & $28^{*}$ & 0 \\
\hline
\end{tabular}

${ }^{*} \mathrm{p}<0.05$ compared with normal and papillary hyperplasia. invasiveness. ${ }^{50}$ They suggested that this discrepancy may be caused by differences in cell or tissue type, and the presence of negative feedback loop.

In summary, COX-2, mPGES-1, $\mathrm{EP}_{2}, \mathrm{EP}_{3}$, and $\mathrm{EP}_{4}$ expression are increased in oesophageal lesions exposed to duodenal contents reflux, and we suggest that the biosynthetic pathway of $\mathrm{PGE}_{2}$ may play an important role in surgically induced oesophageal squamous cell dysplasia and glandular metaplasia.

\section{ACKNOWLEDGEMENTS}

This study was supported by the Dongguk University research fund.

\section{Authors' affiliations}

T J Jang, J I Lee, J R Kim, Department of Pathology, Dongguk University College of Medicine, Kyongiu, Korea

S K Min, Department of General Surgery, College of Medicine Ewha Womans University, Seoul, Korea

J D Bae, K H Jung, W S Ahn, Department of General Surgery, Dongguk University College of Medicine, Kyongiu, Korea

\section{REFERENCES}

1 Kaver WKH, Peters JH, DeMeester TR, et al. Mixed reflux of gastric and duodenal juices is more harmful to the esophagus and gastric juice alone. Ann Surg 1995;222:525-33.

2 Gillen P, Keeling P, Byrne PJ, et al. Implication of duodenogastric reflux in the pathogenesis of Barrett's esophagus. Br J Surg 1988;75:540-3.

3 Pera M, Fernandez PL, Pera M, et al. Expression of cyclin D1 and p53 and its correlation with proliferative activity in the spectrum of esophageal carcinomas induced after duodenal content reflux and 2,6dimethylnitrosomorpholine administration in rats. Carcinogenesis $2001 ; 22: 271-7$.

4 Clark GWB, Smyrk TS, Mirvish SS, et al. Effect of gastroduodenal juice and dietary fat on the development of Barrett's esophagus and esophageal neoplasia: an experimental rat model. Ann Surg Oncol 1994;1:252-61.

5 Pera M, Cardesa A, Bombi JA, et al. Influence of esophagojejunostomy on the induction of adenocarcinoma of the distal esophagus in Sprague-dawley rats by subcutaneous injection of 2,6-dimethylnitrosomorpholine. Cancer Res 1989;49:6803-8.

6 Goldstein SR, Yang G-Y, Curtis SK, et al. Development of esophageal metaplasia and adenocarcinoma in a rat surgical model without the use of a carcinogen. Carcinogenesis 1997; 18:2265-70.

7 Miwa K, Sahara H, Segawa M, et al. Reflux of duodenal or gastro-duodenal contents induces esophageal carcinoma in rats. Int $J$ Cancer 1996;67:269-74.

8 Pera M, Brito MJ, Pera M, et al. Duodenal-content reflux esophagitis induces the development of glandular metaplasia and adenosquamous carcinoma in rats. Carcinogenesis 2000;21:1587-91.

9 Narisawa T, Magadia NE, Weisburger JH, et al. Promoting effect of bile acids on colon carcinogenesis after intrarectal instillation of $\mathrm{N}$-methyl- $\mathrm{N}^{\prime}$-nitro- $\mathrm{N}$ nitrosoguanidine in rats. J Natl Cancer Inst 1974;53:1093-7.

10 Hershman HR. Prostaglandin synthase 2. Biochim Biophys Acta 1996; 1299:125-40.

11 Zhang F, Altorki NK, Wu Y-C, et al. Duodenal reflux induces cyclooxygenase2 in the esophageal mucosa of rats: evidence for involvement of bile acids. Gastroenterology 2001;121:1391-9.

12 Shirbvani VN, Ouatu-Lascar R, Kaur BS, et al. Cyclooxygenase 2 expression in Barrett's esophagus and adenocarcinoma: ex vivo induction by bile salts and acid exposure. Gastroenterology 2000;1 18:487-96.

13 Zimmermann KC, Sarbia M, Weber A-A, et al. Cyclooxygenase-2 expression in human esophageal carcinoma. Cancer Res 1999;59:198-204.

14 Wilson KT, Fu S, Ramanujam KS, et al. Increased expression of inducible nitric oxide synthase and cyclooxygenase- 2 in Barrett's esophagus and associated adenocarcinoma. Cancer Res 1998;58:2929-34.

15 Buttar NS, Wang KK, Olga W, et al. Chemoprevention of esophageal adenocarcinoma by COX-2 inhibitors in an animal model of Barrett's esophagus. Gastroenterology 2002;122:1101-12.

16 DeWitt DL. Prostaglandin endoperoxide synthase: regulation of enzyme expression. Biochim Biophys Acta 1991; 1083:121-34.

17 Jones MK, Wang $\mathrm{H}$, Peskar BM, et al. Inhibition of angiogenesis by nonsteroidal anti-inflammatory drugs: insight into mechanisms and implications for cancer growth and ulcer healing. Nat Med 1999;5:1418-23.

18 Tsujii M, Kawano S, Tsuji S, et al. Cyclooxygenase regulates angiogenesis induced by colon cancer cells. Cell 1998;93:705-16.

19 Tsujii M, Kawano S, DuBois RN. Cyclooxyenase-2 expression in human colon cancer cells increases metastatic potential. Proc Natl Acad Sci U S A 1997; $94: 3336-40$.

20 Tsujii M, DuBois RN. Alterations in cellular adhesion and apoptosis in epithelial cells overexpressing prostaglandin endoperoxide synthase 2. Cell 1995;83:493-501.

21 Murakami $M$, Naraba H, Tanioka T, et al. Regulation of prostaglandin $E_{2}$ biosynthesis by inducible membrane-associated prostaglandin $\mathrm{E}_{2}$ synthase that acts in concert with cyclooxygenase-2. J Biol Chem 2000;275:32783-92. 
22 Tanioka T, Nakatani $Y$, Semmyo N, et al. Molecular identification of cytosolic prostaglandin $E_{2}$ synthase that is functionally coupled with cyclooxygenase-1 in immediate prostaglandin $\mathrm{E}_{2}$ biosynthesis. J Biol Chem 2000;275:32775-82

23 Jakobsson PJ, Thoren S, Mongenstern R, et al. Identification of human prostaglandin E synthase: a microsomal, glutathione-dependent, inducible enzyme, constituting a potential novel drug target. Proc Natl Acad Sci U S A 1999;96:7220-5

24 Stichtenoth DO, Thoren S, Bian H, et al. J Microsomal prostaglandin E synthase is regulated by proinflammatory cytokines and glucocorticoids in primary rheumatoid synovial cells. J Immunol 2001;167:469-74.

25 Yamagata K, Matsumura K, Inoue W, et al. Coexpression of microsomal-type prostaglandin E synthase with cyclooxygenase- 2 in brain endothelial cells of rats during endotoxin-induced fever. J Neurosci 2001;21:2669-77.

26 Filion F, Bouchard N, Goff AK, et al. Molecular cloning and induction of bovine prostaglandin E synthase by gonadotropins in ovarian follicles prior to ovulation in vivo. J Biol Chem 2001;276:34323-30.

27 Satoh K, Nagano Y, Shimomura C, et al. Expression of prostaglandin E synthase mRNA is induced in beta-amyloid treated rat astrocytes. Neurosci Lett 2000;283:221-3

28 Yoshimatsu K, Golijanin D, Paty PB, et al. Inducible microsomal prostaglandin E synthase is overexpressed in colorectal adenomas and cancer. Clin Cancer Res 2001;7:3971-6.

29 Yoshimatsu K, Altorki NK, Golijanin D. Inducible prostaglandin E synthase is overexpressed in non-small cell lung cancer. Clin Cancer Res $2001 ; 7: 2669-74$

30 Jabbour HN, Milne SA, Williams AR, et al. Expression of COX-2 and PGE synthase and synthesis of $\mathrm{PGE}_{2}$ in endometrial adenocarcinoma: a possible autocrine/paracrine regulation of neoplastic cell function via $\mathrm{EP}_{2} / \mathrm{EP}_{4}$ receptors. Br J Cancer 2001;85:1023-31.

31 Kamei D, Murakami M, Nakatani Y, et al. Potential role of microsoma prostaglandin E synthase-1 in tumorigenesis. J Biol Chem 2003;278: 19396-405

32 Ashby B. Co-expression of prostaglandin receptors with opposite effects: a model for homeostatic control of autocrine and paracrine signaling. Biochem Pharmacol 1998;55:239-46.

33 Mutoh M, Watanabe K, Kitamura T, et al. Involvement of prostaglandin E receptor subtype $\mathrm{EP}_{4}$ in colon carcinogenesis. Cancer Res 2002;62:28-32.

34 Watanabe K, Kawamori T, Nakatsugi S, et al. Role of the prostaglandin E receptor subtype $\mathrm{EP}_{1}$ in colon carcinogenesis. Cancer Res 1999;59:5093-6.

35 Sales KJ, Katz AA, Davis $M$, et al. Cyclooxygenase- 2 expression and prostaglandin $E_{2}$ synthesis are up-regulated in carcinoma of the cervix: a possible autocrine/paracrine regulation of neoplastic cell function via $\mathrm{EP}_{2} / \mathrm{EP}_{4}$ receptors. J Clin Endocrinol Metab 2001;86:2243-9.

36 Funkkhouser EM, Sharp GB. Aspirin and reduced risk of esophageal carcinoma. Cancer 1995;76:1116-19.

37 Thun MJ, Namboodiri MM, Calle EE, et al. Aspirin use and risk of fatal cancer. Cancer Res 1993;53:1322-7.

38 Oshima M, Dinchuk JE, Kargman SL, et al. Suppression of intestinal polyposis in Apc $\Delta 716$ knockout mice by inhibition of cyclooxygenase-2 (COX-2). Cell 1996:87:803-9.

39 Kawamori T, Rao CV, Seibert K, et al. Chemopreventive activity of celecoxib, a specific cyclooxygenase-2 inhibitor, against colon carcinogenesis. Cancer Res 1998;58:409-12.

40 Quarles LD, Haupt DM, Davidai $G$, et al. Prostaglandin $F_{2}$ alpha-induced mitogenesis in MC3T3-El osteoblasts: role of protein kinase C-mediated tyrosine phosphorylation. Endocrinology 1993;132:1505-13.

41 Kaur BS, Khamnehei N, Iravani M, et al. Rofecoxib inhibits cyclooxygenase 2 expression and activity and reduces cell proliferation in Barrett's esophagus. Gastroenterology 2002;123:60-7.

42 Liu $\mathbf{X H}$, Kirschenbaum A, Lu $M$, et al. Prostaglandin $E_{2}$ induces hypoxiainducible factor-1 stabilization and nuclear localization in a human prostatic cancer cell line. J Biol Chem 2002;277:5081-6.

43 Fukuda R, Kelly B, Semenza GL. Vascular endothelial growth factor gene expression in colon cancer cells exposed to prostaglandin $E_{2}$ is mediated by hyoxia-inducible factor 1. Cancer Res 2003:63:2330-4.

44 Chen X, Yang CS. Esophageal adenocarcinoma: a review and perspectives on the mechanism of carcinogenesis and chemoprevention. Carcinogenesis 2002;22: $1119-29$

45 Zhang $\mathbf{F}$, Subbaramaiah K, Altorki N, et al. Dihydroxy bile acids activate the transcription of cyclooxygenase-2. J Biol Chem 1998;273:2424-8.

46 Zhang Z, Sheng $\mathrm{H}$, Shao J, et al. Posttranscriptional regulation of cyclooxygenase-2 in rat intestinal epithelial cells. Neoplasia 2000;2:523-30.

47 Narumiya S, Sugimoto Y, Ushikubi F. Prostanoid receptors: structures, properties and functions. Physiol Rev 1999;79:1193-226.

48 Yang L, Yamagata N, Yadav R, et al. Cancer-associated immunodeficiency and dendritic cell abnormalities mediated by the prostaglandin $\mathrm{EP}_{2}$ receptor. $J$ Clin Invest 2003;111:727-35.

49 Amano $\mathrm{H}$, Hayashi I, Endo $\mathrm{H}$, et al. Host prostaglandin $\mathrm{E}_{2}-\mathrm{EP}_{3}$ signaling regulates tumor-associated angiogenesis and tumor growth. J Exp Med 2003;197:221-32.

50 Konger $R$, Scott $G A$, Landt $Y$, et al. Loss of the $E P_{2}$ prostaglandin $E_{2}$ receptor in immortalized human keratinocytes results in increased invasiveness and decreased paxillin expression. Am J Pathol 2002;161:2065-78. 